\title{
Sustainability Transitions: A Survey of an Emerging Field of Research
}

\author{
Pasquale Marcello Falcone \\ Department of Low, Philosophy and Economic Studies - "La Sapienza" \\ University of Rome-Piazzale Aldo Moro, 5, 00185 - Roma, Italy \\ E-mail: pasquale.falcone@uniroma1.it
}

Received: July 19, 2014 Accepted: August 5, 2014

doi:10.5296/emsd.v3i2.6239 URL: http://dx.doi.org/10.5296/emsd.v3i2.6239

\begin{abstract}
With the aim of achieving a sustainable future, the field of transition studies is gathering increasing attention. Particularly, a new research area dealing with "sustainability transitions" has gained ground and reached an output of 70-120 academic articles annually.

In this survey, by carrying out a analysis of fundamental approaches to study transitions (in particular sustainability transitions) we aim at identifying the academic contours of this evolving field of research by highlighting relations among well-known strands of research and by providing some general criticism as well as strengths and contributions from transition research approaches to provide an impetus towards further research in this field.
\end{abstract}

Keywords: Transitions; Innovation studies; Sustainability; Literature review

\section{Introduction}

The study area that has received increasing attention over the last years due to its earnestness is related to the global climate change challenges and its various effects on ecosystems and on resources depletion. Particularly, the consumption and production processes that are taking place worldwide are no more tolerable owing to the limited resource that the planet offers and their inefficient utilizations. Although the majority of these challenges concern environmental and social issues, economic issues are demanding as well. Therefore, the increasing costs of fossil-based raw materials due their scarcity on the one hand, and the need for more sustainable modes of production and consumption on the other, has become a key objective for policy makers and a priority for people.

It is widely believed that persevering in this way is heavily unsustainable and that a transition towards a bio-based economy is seriously needed. However, as emphasized by Geels and Schot 
(2010), transition encompasses long-term "adjustments" involving different scopes (technological, material, organizational, institutional, political, economic, and socio-cultural) of the socio-technical systems. But, often it is easier said than done because these unsustainable systems are profoundly part of the people culture (since they have developed over a substantial time span) making it often "locked-in". For instance, the transition towards a transportation system based on electrical energy suffers infrastructural related problems (i.e. absence of needed recharging stations) that hinder the diffusion of the electric vehicle. At the same time, economic agents are not interesting in financing recharging stations if there are not enough electric vehicles to make it profitable.

In order to better understand the basic dynamics of a transition, several studies have been carried out looking at the theoretical foundations of these changes towards a "green scenario". Such studies are frequently the result of various levels of analysis, even regarding different disciplines, resulting in a variety of approaches aimed at investigating and assessing the sustainability transition patterns. The concern of how to encourage and manage a transition toward a sustainable future has gathered increasing attention either in policy makers' objectives (OECD, 2011; UNEP, 2011) than in academic studies. In conceptual terms, four approaches, to this point, achieved a particular importance in transition studies. These include the multi-level perspective on sociotechnical transitions (Geels, 2002; Geels and Schot, 2007b; Smith et al., 2010), the strategic niche management (Kemp et al., 1998; Raven and Geels, 2010; Smith, 2007), the transition management (Kern and Smith, 2008; Loorbach, 2010), and the technological innovation systems (Bergek et al., 2008; Hekkert et al., 2007).

This paper seeks to provide a description of the most relevant theories and approaches to understand and explain (sustainability) transitions and their related main concepts by examining them and providing some critical considerations in order to have a clear idea about the progresses of sustainability transition studies.

Section 2 highlights the historical overview of the evolution from "transition" concept to the notion of "sustainability transition". Section 3 reviews different approaches to analyse and understand transitions. Then, an overall criticism on these approaches is provided in Section 4, which is followed by a section on the strengths, contributions and potential lines of future research on sustainability transition. The concluding section provides some final thoughts on the topic under investigation.

\section{From Historical Transitions to Sustainability Transitions}

The first literary mention to the concept of "transition" occurred in the 19th century when Alex de Tocqueville ${ }^{1}$ coined such word to depict a revolutionary change in low relationship between master and slave, and described it as an historical phase in which the bourgeois and aristocratic classes did not have anymore a recognized right and thus the strength to stay in power (Lachman, 2013b). During the last 50 years, the concept of transition assumed great relevance in other areas, such as political and power relations to identify the changes that have taken place in economic and social views of some countries. With the collapse of Communist regime

\footnotetext{
1 The Viscount Alexis Henri Charles de Clérel de Tocqueville (Paris, 29 July 1805 - Cannes, 16 April 1859) was a philosopher, political and historical French.
} 
in Eastern Europe and with the fall of the Berlin Wall in 1989, there were the first major transitions in communist countries towards market-based economies. As a consequence, among the social sciences there was the advent of a new discipline called "transitology" (Marody, 1996).

In the 1990s, the "transition" concept was borrowed by researchers involved in sociotechnical studies related to environmental issues. This very area of enquiry had received increasing attention since the 1980s when the World Commission of Environment and Development introduced the concept of "sustainable development" (Lachman, 2013b), defined as the "development that meets the needs of the present without compromising the ability of future generations to meet their own needs" (WCED, 1987) as a global normative aim. This new perspective opened the doors to new interests aimed at investigating transitions towards a sustainable economy. The end of the last century makes "transition studies", especially after that policy makers recognized transition thinking, became a quite relevant field of research so as to diffuse the theoretical approaches on transition theory to better comprehend the basic dynamics of the phenomena and encourage sustainable shifts in the next few years (van den Bosch, 2010).

Within the sociotechnical research context, the concept of "transitions" originally concerned changes of limited ranging within society or essential subsystems (Rotmans et al., 2001). Lately, such idea of "transitions" has been reconsidered in order to explicitly comprehend "the fundamental changes in structure (e.g. organizations, institutions), culture (e.g. norms, behaviour) and practices (e.g. routines, skills)" (Loorbach and Rotmans, 2010). Briefly, the prevailing approach through which a social necessity (e.g. the need for transportation, energy, or agriculture) is met modifies drastically assuming wide-ranging perspective; this might last generally one or two generations (25-50 years) to fully occur (Alkemade et al., 2011). For instance, the issue concerning environmental pollution cannot be faced without profoundly changing the structures of the sociotechnical system. Pollution is the consequence of the inefficiency of our productions and consumption methods, and dealing with these issues entails a long-term transition towards more sustainable processes (Alkemade et al., 2011). Therefore, looking at this goal, a sustainability transitions can be defined as long-term, multi-dimensional, and fundamental transformation processes through which established socio-technical systems shift to more sustainable modes of production and consumption (Geels and Schot, 2010).

According to Geels (2010) sustainability transitions diverge from a mere transitions in the resulting aspects (Geels, 2010):

- Some of new environmental concern will take a conspicuous amount of time to show their effects in tangible way. Therefore, the need of sustainability is not strongly felt so urgent as it should for some other environmental issues (i.e. global warming);

- environmental sustainability requires composite solutions rather than a so-called "magic bullets" as it happens in technological transitions;

- Sustainable transitions often is a policy aim that addresses strategies and decisions of the actors. Therefore, regulation and governance often play an important role (Smith 
et al., 2005).

Due to their intrinsic complexity, transitions towards sustainability cannot be totally planned or forced from the outside, but rather, they could be encouraged and supported with respect to their dimensions by actors that might play the main role (Kemp and Loorbach, 2003).

On this ground, recently the discussion on how to foster and rule a sustainable transition has attracted particular interest in the academic community of researcher in the field of transition analyses. This line of research has become more and more prominent so as to collect an increasing number of publications. Additionally, several institutional structures have been established lately in order to spread the profile of transition studies. The first two international conferences on Sustainability Transitions in 2009 and 2011 have gathered more than 300 academics from all over the world, then a new journal titled "Environmental Innovation and Societal Transitions" was just founded and the Sustainable Transitions Research Network (STRN) was lunched to link transitions researchers and to encourage interchange of knowledge and ideas - www.transitionsnetwork.org - (van den Bergh et al., 2011).

\section{Conceptual Approaches on Transitions}

Sustainable transitions, green innovations, and the advent of eco-friendly technologies have gained consideration in social sciences over the last decade, and several theoretical outlines have been advanced for the analysis of these new dimensions (Grin et al., 2010). This part provides an evaluation of the more prominent transition theories that are believed to be relevant for the conceptual outlining of sustainable transitions. As mentioned in the introduction these are: (1) the Multi-Level Perspective, (2) the Strategic Niche Management, (3) the Transition Management and (4) the Technological Innovation Systems. For the considered approaches, first, it will be outlined the theoretical background, then, it will be discussed the essential notions and sights on transitions, and finally, it will be addressed strengths and drawbacks. However, It should be emphasized that the above-mentioned approaches are not the totality of the proposed ones, but rather the more considered and studied. In this context, it is important to consider that there are several other important theoretical frameworks that have been taken into account to assess and describe the peculiarities of different transition patterns. These involve common theories, such as evolutionary economic theory (Nelson and Winter, 1982) and actor network theory (Law and Hassard, 1999), as well as lines with a more explicit emphasis on technological changes (Bijker et al., 1987).

We will restrict the next subsection on the review and analysis of the aforementioned four approaches, since they embrace general and systemic views of socio-technical systems.

\subsection{Multi-Level Perspective}

The Multi-Level Perspective (MLP) is an approach dealing with, inter alia, the complex issue of sustainable development. It is a mix between evolutionary theory approaches and patterns of long-term changes. Particularly, it seeks to explain sociotechnical transitions through the interaction of three different levels: macro, meso and micro level - these corresponding correspondingly to landscape dynamics, technological regimes and innovation niches (Rip and Kemp, 1998; Geels, 2002). 


\section{Macrothink Institute ${ }^{T M}$}

Landscape (macro) refers to the overall socio-technical setting that comprehends both the intangible aspects of social values, views and political beliefs and the tangible aspects involving the institutions and the functions of the marketplace such as prices, costs, trade patterns and incomes. Therefore, it represents the set of elements or factors that can have a significant impact on the meso (regime) and micro (niche) levels.

Regime (meso) refers to the dominant practices, rules and technologies that provide stability and reinforcement to the prevailing socio-technical systems (Geels, 2004). Namely, the sociotechnical regime involves three interdepended elements: (i) a network of actors and social groups that adapts over time to the system dynamics; (ii) the set of formal and informal rules that address the behaviours and the actions of actors in order to preserve and steer the nature of the socio-technical system; (iii) the set of material and technological components.

Niche (micro) a frequently used description for niches is a protected space, i.e., particular environments, in which radical innovations can mature away from the selective pressures of the main socio technical regime (Kemp et al., 1998).

In accordance with the MLP, transitions arise as a consequence of shocks at various levels. Landscape dynamics could put pressure on current regimes and open windows of opportunities for niches to exploit and conduce to important transitions in socio-technical regimes.

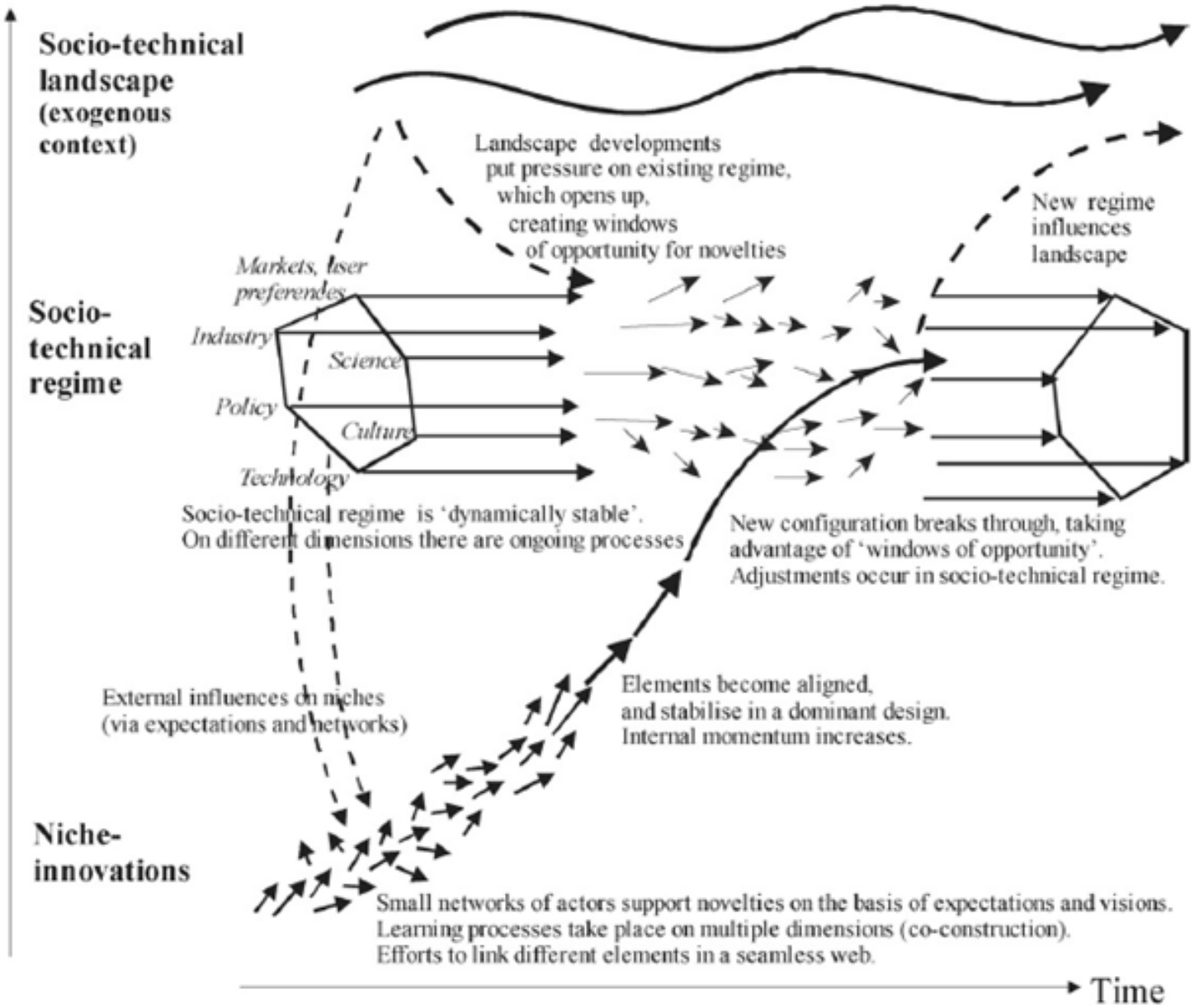

Figure 11. Multi Level Perspective on Transitions (Geels, 2002). 
Geels and Schot (2007) develop a typology of four transition pathways: transformation, reconfiguration, technological substitution, and de-alignment and re-alignment. The following pathways differ in combinations of timing and nature of multi-level interactions:

- Transformation path: modest landscape dynamics during the niches seed phase, bring regimes to respond by adjusting the trend of development and innovation initiatives.

- De-alignment and re-alignment path: if landscape pressures are different, big and unexpected they will increase regime difficulties and give rise to the de-alignment. The lack of adequately advanced niches, developing niches will contend to succeed and only one niche will become central, leading to re-alignment of an innovative socio technical regime.

- Technological substitution: substantial landscape pressure mixed with adequately established niches gives rise to deposing of regimes by niches, which will break through and replace the existing regime.

- Reconfiguration pathway: symbiotic innovations, which are developed in niches, are initially adopted in the regime to solve local problems. They subsequently trigger further adjustments in the basic architecture of the regime.

These transition pathways contrast with the so-called reproduction process which occur in the absence of landscape pressures. Under this circumstance the regime remains dynamically stable and will reproduce itself. Radical niche-innovations might appear, but they have few possibilities to succeed as long as the regime is dynamically stable.

The MLP is a valuable theoretical approach in terms of scope and generalizability (since it succeeds in approaching different and complex situations) that aims to provide a real perspective of transitions in order to address the study of patterns, causes and impacts of different phenomena in transitions processes (Geels, 2011). Therefore, the MLP approach has been able to describe past (Geels, 2002, 2007) and current transitions (Kern, 2012; Nakamura et al., 2012). Despite the great success and attention achieved by the MLP approach, it has not escaped from criticism on three general points. The first critique regards empirical and analytical aspects. For example, Berkhout et al. (2004, p. 54) state: "it is unclear how these conceptual levels should be applied empirically. By this we mean that a sociotechnical regime could be defined at one of several empirical levels". In the electrical sector one might analysis a regime by looking at the primary fuel (coal, oil, gas) or by enlarging the analysis at the whole system (production, distribution and consumption of electricity). Therefore, what seems a regime shift at one stage might be perceived simply as an incremental transition in inputs for a broader regime. The second critique is the relative overlook of agency, particularly in representations (communities and interacting groups) such as Fig. 1. For example, Smith et al. (2005: 1492) state: "MLP is overly functionalistic. Despite the breadth of the regime concept, there is a tendency to treat regime transformation as a monolithic process, dominated by rational action and neglecting important differences in context. We also argue that existing approaches tend to be too descriptive and structural, leaving room for greater analysis of agency". The last critique concerns the great relevance that the approach recognizes on 
technological niches as the most important locus for the regime shift. For example, Berkhout et al. (2004, p. 62) argue: "MLP-approaches are unlinear in that they tend unduly to emphasize processes of regime change which begin within niches and work up, at the expense of those which directly address the various dimensions of the sociotechnical regime or those which operate 'downwards' from general features of the sociotechnical landscape”.

In spite of these criticisms, defined constructive by Geels and Schot (2007), the MLP has gathered an increasing attention and academics are constantly contributing to the concept by focusing on topics such as interaction between niches and regimes, definition of operational limit, further interactions among the proposed levels, and empirical assessment of concepts. Moreover, the MLP is a valuable tool for policy makers to understand and thus, to address transitions in an efficient and effective way by placing the focus on both niche and regime levels (Geels, 2012).

\subsection{Strategic Niche Management}

Strategic Niche Management (SNM) is a recently developed analytical approach that is proposed expressly to enable the introduction and diffusion of very new sustainable innovations through societal experiments. SNM scholars state that for several new technologies, mainly with sustainability aims, market niches and consumer demand are not immediately available since the innovations are not always trivial changes from the prevailing set of technologies, but differ deeply from them. SNM was therefore designed to entail the management of particular type of innovations: (1) socially desirable innovations serving long-term goals such as sustainability, (2) radical novelties that face a divergence with regard to existing infrastructure, user practices, regulations, etc. It is indeed for this reason that SNM scholars see real-world experimental projects, in which various stakeholders collaborate and exchange information, knowledge and experience, as important devices that precede market niche development (Schot and Geels, 2010).

Pioneering studies on SNM (see Kemp et al, 1998) theorized the process as a bottom-up process, in which innovations arise in technological niches, then under some critical circumstances achieve market niches, and finally replace and renovate the regime. The main research question, hence, was: how and under which conditions the successful emergence of a technological niche is achievable?

Grounded on a series of considerations from innovation studies, three internal mechanisms have been single out for technological niche to succeed (Elzen et al., 1996; Kemp et al., 1998; Hoogma et al., 2002): (i) expectations considered crucial for niche development because they provide direction to learning processes, (ii) learning process at multiple dimension (technical, cultural, infrastructural, societal and environmental) and (iii) network formation to create a constituency behind the new technology.

Firstly, expectations and visions, when positive, are necessary to "pull in" attention, resources and new actors potentially interested, especially, when the technological innovation is still in a early phase of development and its performance is still uncertain. Expectations also provide direction to development: they act as cognitive frames for making choices in the design process. 
Expectations will contribute to successful niche development if: they are robust (shared by more actors), they are specific (if expectations are too general they do not give any guidance), and they have higher quality (the content of expectations is substantiated by on-going projects) (Kemp et al., 1998; Hoogma et al., 2002).

Secondly, learning process is generally recognized essential for successful innovation (Kemp et al. 1998). Learning will arise both individually (as producers will increase their knowledge simply "by doing") and collectively. This second option suggests that firms and other actors involved in the technological niche will share their own knowledge (Lopolito et al., 2011).

Finally, building of social networks is important to facilitate interactions between relevant stakeholders, and provide the necessary resources (money, people, expertise). The formation of social networks is likely to contribute more to niche development if: the networks are broad, i.e. multiple kinds of stakeholders are included to facilitate the articulation of multiple views and voices; the networks are deep, i.e. people who represent organisations, should be able to mobilise commitment and resources within their own organisations and networks through regular interactions (Elzen et al., 1996; Hoogma et al., 2002).

The above hypotheses were examined in a European Union project ${ }^{2}$ and reviewed, criticised or edited in some other studies. These studies encompassed empirical (case) studies of completed and/or on-going experiments in a series of fields, from transport to energy to agriculture and sanitation, mainly in European contexts, but also in Tanzania and South Africa (see for instance, Caniels and Romijn, 2007; Van Eijck and Romijn 2008; Lopolito et al. 2011). Some of them examined if the recognized success conditions would have been able to justify the outcomes. The selected case studies involved some examples of market niche development, but many of them showed a limited outcome in terms of boosting further niche development into a sustainable path.

Some other studies emphasize weaknesses of the SNM approach as defined in Kemp, Schot, and Hoogma (1998) and Hoogma et al. (2002). For example, Brown et al. (2004) and Harborne et al. (2007) pointed out that participation of external actors and second-order learning do not occur certainly and by themselves. It requires the presence of particular drivers and circumstances. They point to the importance of a sense of urgency and the role that a process of structured repeated visions might play. Similarly, Hegger and van Vliet (2007) state that the major focus on experiments with technological enhancement in many demonstration projects gives not rise to broad learning and outsider involvement. They suggest redirecting the focus of niche experiments towards concepts, visions and guiding principles rather than on defined technologies, and toward experimentations with social aspects and acceptance before without neglecting the socio-technical character of the transition process. Against this background, the transition management (TM) approach, which will be discussed thereafter, supported by Rotmans, Loorbach and others might help to overcome some weaknesses by integrating the

\footnotetext{
${ }^{2}$ In 1998, the European Union funded a SNM research project within the "Environment and Climate" RTD programme. Through this project, scholars in several countries contributed on SNM. They investigated fourteen innovative transport projects in different European cities (ranging from electric vehicles to car sharing schemes). This collaborative project resulted in a workbook for practitioners on how to do SNM (Weber et al. 1999), and an academic book (Hoogmaet al. 2002).
} 
SNM approach. In facts, TM highlights either the importance of experiments than the necessity of creating visions before starting experiments (Rotmans et al., 2001; Loorbach 2007).

\subsection{Transition Management}

Transition management (TM) matches the study on technological transitions with insights from complex systems theory (e.g., Kauffman, 1995) and governance approaches (Rotmans et al., 2001; Smith et al., 2005). TM scholars have provided and applied an instrumental, practice-oriented model for influencing on-going transitions into more sustainable directions by combining long-term thinking with short term action (thus complementing conventional policy) through a process of searching, experimenting and learning. It is innovative for two orders of reasons: It offers a prescriptive approach toward governance as a basis for operational policy models, and it is explicitly a normative model by taking sustainable development as long-term goal (Loorbach, 2010). According to Loorbach and Rotmans (2006), the TM key aspects are: (i) continuous processes of experimentation and learning to address variations and selections along the transition process (learning-by-doing and doing-by-learning) while not chasing "silver bullets" (thus keeping all possible options in consideration and the field open); (ii) consideration of all possible actors (stakeholder from multiple domains and levels) obtaining input through their inclusion and involvement; (iii) complementation of conventional policy (which typically has a short-term focus) with long-term thinking with the aim of sustainable development by creating required expectations before starting experiments; (iv) continuous analysis of the feedbacks (monitoring, evaluating, improving) on all levels in order to bring system innovation alongside system improvement.

The scholars' challenge has been to translate these theoretical aspects into a practical management framework without losing too much of the complexity and, at the same time, without becoming too descriptive. Loorbach and Rotmans (2006) and Loorbach, (2010) tried to develop a framework for transition management by combining practical experiment and real observation. Namely, it is based on "usual" processes of governance that can be seen in society (see, for instance, Kemp 2006 and Parto et al. 2007) but it is structured and distinct on the basis of the characteristics of complex societal transitions. In the transition management framework, four different governance levels (alternatively called "spheres") are recognized to be significant for sociotechnical transitions (Loorbach, 2010):

- Strategic level: a transition arena, a small network of strategic discussions, long-term goal formulation, collective goal and norm setting, and long-term anticipation. Simply, all activities and their developments that deal mainly with the ethics of a societal system as a whole: debates on norms and values, identity, culture, sustainability and relative importance for society.

- Tactical level: steering activities regarding the dominant structures (regime) of a sociotechnical system. This includes all established patterns and structures, such as rules and regulations, institutions, organizations and networks which allow to implement a transition agenda towards the desired goal with the consent of regimes, by aligning them with the long-term goal. 


\section{Macrothink}

- Operational level: experiments and actions that are identified by a short-term horizon and carried out in the context of innovation projects and programs, in business and industry, in politics or in civil society to stimulate learning and thus to enable adaptations in transition pathway.

- Reflexive level: reflexive activities relate to monitoring, assessments and evaluation of on-going policies, and on-going societal change. In part, they are located within existing institutions established to monitor and evaluate, but in part they are also socially embedded: The media or internet, for example, have an important role in influencing public opinions and judging the effectiveness of policies and political agendas.

The three levels described above follow a cyclical path (Fig. 2) consisting of problem structuring and envisioning (strategic level), agenda building and networking (tactical level), experimenting and diffusing (operational level), evaluating, monitoring, and learning (reflexive level) (Loorbach, 2010).

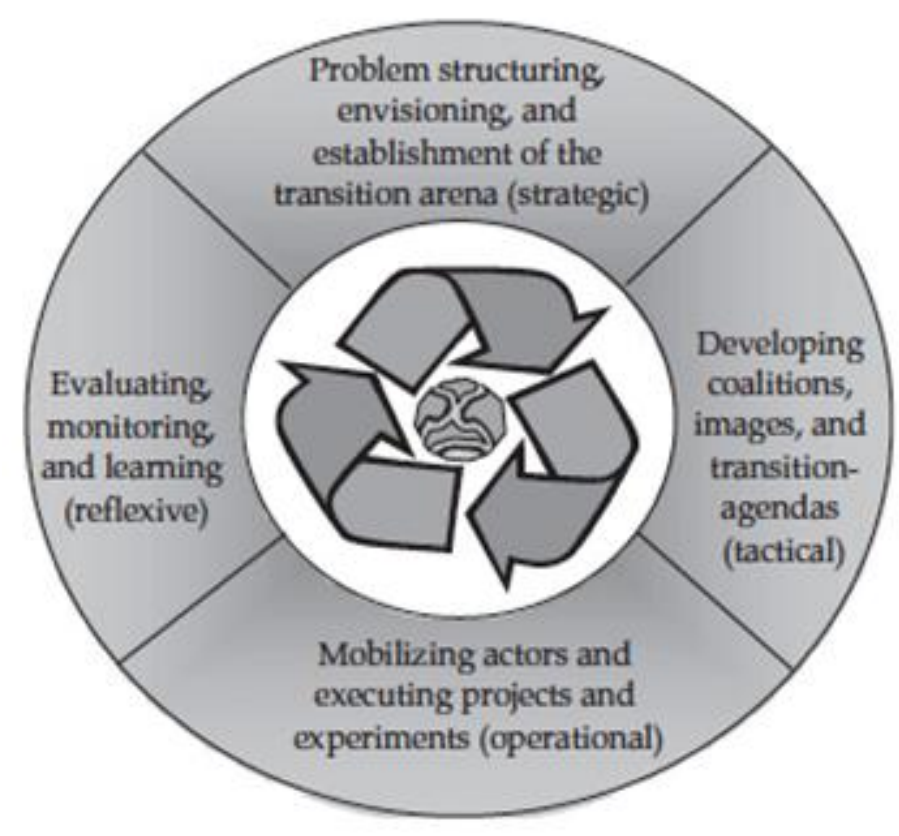

Figure 22. Transition Management Cycle (Loorbach, 2010).

The transition management framework offers the basis for managing transitions in an operational sense. Although every transition management process will be unique in terms of context, actors, problems, and solutions, the cycle is flexible enough for adaptation but direct enough to be functional in practice. An integrated analysis of a societal system in transition terms yields a very general idea of the dynamics in society on different levels that are a starting point for governance (Loorbach and Rotmans, 2006).

A further theoretical tool that is attracting more attention about the TM approach is the "transition scenario" that is a description of reasonable developments that follows a possible 
end-state. Transition scenarios help to predict abrupt deviations from trends, align and involve multiple stakeholders, keep options open, and contribute to learning (Sondeijker et al., 2006; Wiek et al., 2006). The methodology to comprehend transition scenarios is identical to the traditional scenario planning methodology (Lachman, 2011).

So far the concept of transition management has been received as promising and pointing into the right direction and has been applied quite extensively in the last decade. However, transition management is not exempt from criticisms. An overall criticism that arises in literature regards the one crucial point of transition management. That is, the claim that deliberate and systemic intervention in pursuit of sustainable goals is possible and potentially effective. Research on historical transitions shows, however, that several transitional changes were unplanned or not originally predicted ('spontaneous change'). But, as Meadowcroft (2007) says, this does not mean that addressing societal processes in order to achieve required changes is unlikely. Conversely, policy makers have often focused on and influenced transition processes, e.g. in the fields of energy, waste, agriculture and water (Loorbach et al., 2007), but typically on a smaller and more modest scale than the one proposed by transition management. Another sharp criticism was proposed by Shove and Walker (2008) who rejected the basic idea of $\mathrm{TM}$ as a tool able to explain that a transition can be accomplished mostly through the execution of proper management, so that transitioning is purely a managerial task. By claiming that TM scholars simplify the scope of the transition task by neglecting the fact that influences exist - both inside and outside the transition management context - such as belief systems, political interests, and culture, which hinder or even prohibit managing transitions according to best management practices and rules. Finally, another criticism that has been advanced pertains to the bias towards the incumbent regimes actors that recognizes little importance to the actors on the niche levels. This is evident in the lack of tools, practices, models etc. employed to empower niches in order to break through into the mainstream (i.e. the regime level) (Kern and Smith, 2009).

\subsection{Technological Innovation Systems}

Research on technological innovation systems (TIS) has developed constantly during the last twenty years to the point of becoming the fourth major line of analysis in the arena of transition studies. The TIS is an approach developed within the scientific field of innovation studies which serves to explain the nature and rate of technological change and can be defined as a dynamic network of agents interacting in a specific economic/industrial area under a particular institutional infrastructure and involved in the generation, diffusion, and utilization of technology (Carlsson and Stankiewicz, 1991). TIS can be described as the combination of all institutional and socioeconomic structures that affects both the direction and the speed of technological change in society. Therefore, the central idea behind this approach is that determinants of technological change are not only to be found in individual firms, in research institutes or in policy intervention, but also in a broad societal structure in which firms, governments, as well as knowledge institutes, are embedded (Hekkert et alt., 2007).

Since these early days, the TIS approach developed numerous theoretical refinements (Carlsson et al., 2002) and one of the most significant has been the specific identification of key 
processes, so-called functions, which need to occur smoothly for the system to perform well (Bergek et al., 2008; Hekkert et al., 2007). Recently, TIS studies have moreover, developed a greater focus on specific technologies (Hekkert et al., 2007), which is different from prior studies that considered generic technologies at the core of the analysis. This shift in focus is accompanied with greater attention to radical (and often more sustainable) innovations in an early stage of development with a potential to challenge established socio-technical systems. In other words, the analytical interest has shifted from technological innovation contributing to the economic growth of countries to new technologies as cores for fundamental sociotechnical transitions (Markard et al., 2012).

The main TIS's idea is to "decompose" technological systems in order to split every single component and by analysing them to discover which system elements do not accomplish their intended purpose, thereby hindering the development of the whole system (Jacobsson and Bergek, 2010). The system components of TIS are called structures. These represent the static aspect of the system, as they are relatively stable over time. Three basic categories are distinguished (Hekkert et al., 2007):

- Actors: They involve organizations contributing to a technology, as a developer or adopter, or indirectly as a regulator, financier, etc. It is the actors of TIS that, through choices and actions, actually generate, diffuse and utilize technologies. The potential variety of relevant actors is enormous, ranging from private actors to public actors, and from technology developers to technology adopters. The development of TIS will depend on the interrelations between all these actors. For instance, entrepreneurs are unlikely to start investing in their businesses if governments are unwilling to support them financially.

- Institutions: Institutional structures are at the core of the innovation system concept. It is common to consider institutions as "the rules of the game" in a society. A distinction can be made between formal institutions and informal institutions, with formal institutions being the rules that are codified and enforced by some authority, and informal institutions being more tacit and organically shaped by the collective interaction of actors.

- Technological factors: Technological structures consist of artefacts and the technological infrastructures in which they are integrated. They also involve the techno-economic workings of such artefacts, including costs, safety or environmental sustainability. These features are crucial for understanding the feedback mechanisms between technological change and institutional change.

The structural factors are merely the elements that make up the system and the basic idea of this approach is to consider all activities that contribute to the development, diffusion, and use of innovations as system functions. Therefore, TIS follows the same approach of the "reverse salient" ${ }^{\prime 3}$ introduced by Hughes (1983) and used in the Large Technical Systems approach. In

\footnotetext{
${ }^{3}$ Thomas P. Hughes introduces the concept in the analysis of technological systems, whereby the reverse salient refers to a component of the system that, due to its insufficient development, prevents the technological system in its entirety achieving its targeted development.
} 
other words, technological systems may refer to a hierarchically nested structure of technological parts, whereby the system is seen as a composition of interdependent sub-systems that are themselves systems including more sub-systems. Moreover, technological systems might be seen as socio-technical systems that include, in addition to technical sub-systems, social sub-systems, such as the planner and material creators of technology and its users, as well as the supervision of regulatory subjects. This makes the approach very interesting for policy makers because it allows identifying at each level a possible bottleneck in transition processes. In fact, from their beginning, many analyses of technological innovation systems were intended to actively involve policy makers in the identification of drivers and barriers to innovation systems (Negro and Hekkert, 2008). In this context, one of the major contributions of the innovation systems perspective is that it has left behind the narrow concept of market failures and replaced it with a broader set of system failures, involving weakly working networks, institutional failures, infrastructure failures, etc. (Bergek et al., 2008). This, combined with the above-mentioned change of focus toward technology-specific innovation systems, has paved the way for suggesting technology-specific policies on the basis of TIS studies (Jacobsson and Bergek, 2011).

Despite the importance and attention achieved by the TIS approach, it has not been without criticism on transition dynamics. First of all, as claimed by Geels (2011), it is a multi-dimensional approach (although cultural and demand side aspects are under-developed), which does not address structural changes and do not look at interactions between new entrants and incumbents, but tend to focus only on technology and market dimensions (for instance, in terms of how emerging innovations struggle against existing systems). Secondly, it focuses more on the functioning of systems, particularly, in discovering the weaknesses of elements, rather than overall system changes. Therefore, mostly of emphasis is given on identifying system weaknesses, neglecting oftentimes their development and the reasons behind these weaknesses. As a consequence, a little attention is given to system dynamics (Smith et al., 2010). Finally, TIS approach place more focus on powerful actors, such as institutions and firms, and tends to neglect smaller one, such as grass roots movements and individuals (Geels, 2011).

Although these criticisms, the TIS approach has been strongly developed by some scholars, in particular in the 1990s, and has become one of the strands of research on (sustainability) transitions (Alkemade et al., 2011), even if it is argued that it has not evolved into a broader understanding of transitions (Smith et al., 2010).

\section{General Critique}

Despite the approach-specific considerations and limitations that have been emphasized in the section above, there are some important aspects concerning in general the theoretical approach of transition to be considered. These considerations needs to be taken into account in order to optimize and to update the proposed approaches by making them more inclusive, applicable for different backgrounds, appropriate for a broader focus regarding transitions, or at least make users aware of the weaknesses that are intrinsic to these approaches (Lachman, 2013b). A set of general and critical considerations concerning the approaches studying (sustainability) 
transitions are reported hereafter.

- Approaches investigating transitions are profoundly characterized by the ambit in which they were envisaged and could, hence, be less appropriate for other environments. A clear issue concerning such limitation is the substantial difference between so-called developed and developing countries (Lachman, 2013); they diverge on social, behavioural, environmental and political aspects. An example is the fact that in developing countries the best part of technology, if not all, is not domestically developed, but rather imported from developed countries. As a result, the knowledge at the base of the technology often does not follow the technology, but rather remains "locked" in the country of origin. An additional example can be found in the rapid rate of development, population growth, and urbanization in developing countries that straightens other relevant objectives for policy makers (i.e. employments, standards of living, etc.) rather than transition toward sustainability, thus implicitly reinforcing current regimes to a degree that is hardly the case in developed countries. These cases show that context-specificity can have a remarkable effect on the success or failure of a transition; thus, even if notable efforts has been provided, from scholars, in the field of energy system transitions and important research achievements have come to light, it should be noted that studies on transition have been largely addressed and confined to its origin, that is, in developed countries, and hence approaches to investigate these transitions originated in developed countries should therefore be tested in other geographical and socio economical contexts and be adjusted consequently. It is important to report here that some studies have been carried out in specific Asian developing countries (Berkhout et al., 2010; Rehman et al., 2010; Romijn et al., 2010; Verbong et al., 2010), but these cannot be considered representative for other countries outside the Asian context.

- Approaches analysing transitions also suffer from a strong bias towards producers/suppliers perspective (Verbong et al., 2008). Focus is heavily linked to the innovation-process; see for example the meanings that have been assigned to the niche-concept, only (lately) broadened in scope by Geels (2007). Consequently, attention is almost entirely dedicated to producers, suppliers and institutional networks, while transitions concerning mainly the activities related to consumer/user are much less considered. Against this background, there is an open ground that needs to be filled in since one of the most salient aspects regarding sustainability transitions is the fact that, in order to achieve the target of sustainable development, existing modes of production and consumption (in particular regarding energy resources, food and water) are earnestly in need of a shift toward sustainability.

- The application of the approaches appears, in some circumstances, quite complex and lacks in consistency. To have an idea, in a survey of the transitions literature, Raven et al. (2010) found five different meanings of the regime concept, six different meanings of the niche, and four different meanings of the landscape. Genus and Coles (2008) have found, for example, that MLP is applied unsystematically 
across different studies and that transitions researchers repeatedly omit justification of choices and interpretations. At the same time, the unit of analysis is far from clear in the theory and involves both strategic choices and political decisions (Walker and Shove 2007). Therefore, an effort should be made by researcher in order to have a unity of purpose, a clear justifications and definition of the aforementioned sociotechnical elements.

\section{Strengths, Contributions and Potential Lines of Future Research}

Apart from the aforesaid general critiques on transition research, there are some important strengths and contributions that need to be emphasized and which create the bases for further developments of this field of research.

As mentioned in section 3 above, some studies conducted over the last years helped expanding the scope of the research on transitions with regard to developing countries. Although still at an early stage, a growing number of transition studies in developing countries are carried out by scholars from developing nations, which are currently contributing with their research by developing transition models and implementing transition experiments, etc. This is the confirmation that sociotechnical transition toward sustainable future is being increasingly considered worldwide.

An important contribution from transition research to highlight is the fact that transition scholars are open to venture into uncharted territory by applying transition thinking in different disciplines and using ideas and concepts from these disciplines to advance transition thinking (Geels, 2010). Some examples are insights from social movement theory and political science used to deepen the Multi-Level Perspective (Elzen et al., 2011), and the steps taken to link transition thinking in urban and spatial planning (Coenen et al., 2012; Hodson and Marvin, 2010). Such openness and dynamism makes researcher free from the risk to be trapped in their own discipline while analysing transitions. The possibilities to interact with other disciplines are practically infinite, and the fact that transition scholars seek to synergize with other subjects is an explicit advantage to exploit for future development of this field of research.

\subsection{Major Lines of Future Research in Transition Studies}

This subsection considers four wider lines of potential research on sustainability transition studies that we derived from the analysis of the literature on the topic, including several special issues, e.g., Smith et al. (2010) and van den Bergh et al. (2011), and the manifest of the STRN network (STRN, 2010) and aim at providing a fertile ground of investigation as well as a solid framework for future analysis (Markard et al, 2012).

First, there is a specific necessity to think out and better specify the theoretical frameworks and methodological foundations for comprehending both historical and current transitions. This implies to challenge the prevailing theoretical approaches in terms of where and how they can be implemented, which are their constraints, up what ontological considerations they are grounded, etc. Against this background, there have been some recent discussions on the strengths and weakness of the multilevel perspective approach (Geels, 2011; Markard and Truffer, 2008), which not only allows making the framework more accurate and reliable, but 
might also conduct to a more exact application in empirical analyses. Moreover, we believe that there is a lot to know from established ideas and frameworks in other disciplines and such additional knowledge could be used in a complementary way to provide more consistent explanations. Consequently, enhancements in the conceptual approaches on transition studies will have implications for the methodological styles that will be prevalent in transition research as well.

Second, considering the importance in nowadays transitions of transition-based policy concepts, such as strategic niche management or transition management, there is a critical need to better understand the role of the politics and policies on sustainability transitions processes. Conceptually, topics concerning the power and politics have initially been quite neglected (Meadowcroft, 2009; Shove and Walker, 2007). Only lately these issues began to be fairly considered given that they represent quite an important line of research activity in transition studies (Avelino, 2011). At a more operational level, further research is required to better understand and specify the long-term effects of specific policies on sustainable transitions in order to develop and and implement of new policy frameworks to make transition activities carried out at different levels more effective.

A third domain in which further research appears to be quite promising relates to the understanding of the agency of different actor groups in the context of transition processes (Raven et al., 2011). Strategies of firms and other actors or the role of strategic unions within industries did not collect the necessary consideration in the existing body of literature on socio-technical transitions. While green innovation is one of the core drivers for fundamental shifts in industry structures, transition research has predominantly focused on meso-level contexts, such as innovation systems and sociotechnical regimes neglecting, for example, the role of civil society and cultural movements in transition processes. Therefore, the field might benefit from more in-depth studies on how system and regime structures are created and changed through the strategic interplay of different types of actors at each level (Musiolik and Markard, 2011).

Finally, there has been an increasingly attention over the past few years in addressing more explicitly the geographical dimension of historical and emerging transition processes (Coenen and Truffer, 2012). This will have implications on the conceptual level of the transition approaches, i.e. by addressing the differentiation of regime, niche, and innovation system structures in particular regions of the world. It also has strong empirical implications in that transition processes happening in developing countries that have not received, to this point, adequate attention in the literature, and their inclusion may require further conceptual work. Therefore, more research is needed on transition approaches - and their suitability - in developing economies that perhaps are the most needy of transition towards sustainable futures.

Addressing these issues more explicitly would eventually enable the analysis of transition processes and the specification of related approaches in a truly "global" perspective, which is what many of the global environmental change problems, such as climate change or biodiversity management, ultimately will require (Coenen and Truffer, 2012) 


\section{Conclusions}

Sustainability transition arena represent a fertile ground for research, given the importance and indispensability of sustainability challenges we are facing today. It has evolved quite notably in last years, with a sharp increase of the number of papers published, special issues on a variety of subtopics, and the development of institutional structures, such as the STRN network, fostering the establishment of a research community (Markard et al, 2012). However, sustainability transition is a field manifold because of the large number and variety of actors and interests concerned in transition processes.

This paper tried, in the hopes of the author, to provide a description of the most relevant theories and approaches to understand and elucidate (sustainability) transitions and key related concepts. At this end, the work has a critically reviewed the transition theoretical approaches and related dynamics separately, providing on the one hand, both some general and specific criticism and, on the other hand, highlighting important strengths, contributions and potential line for future research.

We believe that improving conceptual and methodological approaches is one important issue on the research agenda, but providing further empirical insight is certainly another. Therefore, there is still some significant work that needs to be done, and fortunately the open and dynamic nature of transition research makes it possible to adopt ideas to develop the transition research field by enlarging the focus in other disciplines and context (i.e. developing countries). This is very promising and transition researchers must consider such possibility, not only to understand sustainability transitions, but also to find a way to affect them in order to mitigate the impacts resulting from the on-going climate change.

\section{References}

Ahman, M., Nilsson, L. J., (2008). Path dependency and the future of advanced vehicles and biofuels. Utilities Policy 16, 80-89. http://dx.doi.org/10.1016/j.jup.2007.11.003

Alkemade, F., Hekkert, M.P., Negro, S.O., 2011. Transition policy and innovation policy: friends or foes? Environmental Innovation and Societal Transitions 1 (1), 125-129. http://dx.doi.org/10.1016/j.eist.2011.04.009

Avelino, F., 2011. Power in Transition. Empowering Discourses on Sustainability Transitions. Erasmus University, Rotterdam.

Bergek, A., \& Jacobsson, S., (2003). The Emergence of a Growth Industry: A Comparative Analysis of the German, Dutch and Swedish Wind Turbine Industries. In: Metcalfe, J.S., Cantner, U. (Eds.), Change, Transformation and Development. Physica-Verlag (Springer), Heidelberg, pp. 197-228. http://dx.doi.org/10.1007/978-3-7908-2720-0_12

Bergek, A., Jacobsson, S., Carlsson, B., Lindmark, S., \& Rickne, A., (2008). Analyzing the functional dynamics of technological innovation systems: a scheme of analysis. Research Policy 37, 407-429. http://dx.doi.org/10.1016/j.respol.2007.12.003

Berkhout, F., Angel, D., \& Wieczorek, A. J., (2009). Sustainability transitions in developing 
Asia: are alternative development pathways likely? Technological Forecasting and Social Change 76, 215-217. http://dx.doi.org/10.1016/j.techfore.2008.04.003

Berkhout, F., Verbong, G., Wieczorek, A. J., Raven, R., Lebel, L., \& Bai, X., (2010). Sustainability experiments in Asia: innovations shaping alternative development pathways? Environmental Science \& Policy 13, 261-271. http://dx.doi.org/10.1016/j.envsci.2010.03.010

Bijker, W. E., Hughes, T. P., \& Pinch, T. J., (1987). The Social Construction of Technological Systems: New Directions in the Sociology and History of Technology. MIT Press, Cambridge/MA.

Brown, J., Gillooly, J., Allen, A. Van M. Savage, \& Geoffrey B. West. (2004). Toward A Metabolic Theory of Ecology. Ecology 85, 1771-1789.

Carlsson, B., Jacobsson, S., Holmén, M., \& Rickne, A., (2002). Innovation systems: analytical and methodological issues. Research Policy 31, 233-245. http://dx.doi.org/10.1016/S0048-7333(01)00138-X

Coenen, L., Benneworth, P., \& Truffer, B., (2012). Towards a spatial perspective on sustainability transitions. Research Policy 41(6), 968-979. http://dx.doi.org/10.1016/j.respol.2012.02.014

Coenen-Huther, J., (1996). Transition as a topic for sociological analysis. In: Sztompka, R. (Ed.), Building Open Societies and Perspectives of Sociology in East-Central Europe. ISA

Fischer-Kowalski, M., \& Rotmans, J., (2009). Conceptualizing, observing, and influencing social-ecological transitions. Ecology and Society, 14(2).

Fischer-Kowalski, M., (2011). Analyzing sustainability transitions as a shift between socio-metabolic regimes. Environmental Innovation and Societal Transitions, 1(1), 152-159. http://dx.doi.org/10.1016/j.eist.2011.04.004

Geels, F. W. (2005). Technological Transitions and System Innovations: A Co-evolutionary and Socio-Technical Analysis. Edward Elgar, Cheltenham. http://dx.doi.org/10.4337/9781845424596

Geels, F. W. (2006). Co-evolutionary and multi-level dynamics in transitions: the transformation of aviation systems and the shift from propeller to turbojet (1930-1970). Technovation, 26, 999-1016. http://dx.doi.org/10.1016/j.technovation.2005.08.010

Geels, F. W. (2007). Analysing the breakthrough of rock 'n' roll (1930-1970). Multi-regime interaction and reconfiguration in the multi-level perspective. Technological Forecasting \& Social Change, 74, 1411-1431. http://dx.doi.org/10.1016/j.techfore.2006.07.008

Geels, F. W. (2010a). Ontologies, socio-technical transitions (to sustainability), and the multi-level perspective. Research Policy, 39(4), 495-510. http://dx.doi.org/10.1016/j.respol.2010.01.022

Geels, F. W. (2011). The multi-level perspective on sustainability transitions: responses to seven criticisms. Environmental Innovation and Societal Transitions, 1(1), 24-40. 
Geels, F. W., \& Schot, J. (2007). Typology of transition pathways. Research Policy, 36, 399-417. http://dx.doi.org/10.1016/j.respol.2007.01.003

Geels, F. W., (2002). Technological transitions as evolutionary reconfiguration processes: multi-level perspective and a case study. Research Policy 31, 1257-1274. http://dx.doi.org/10.1016/S0048-7333(02)00062-8

Geels, F. W., (2004). From sectoral systems of innovation to socio-technical systems: insights about dynamics and change from sociology and institutional theory. Research Policy, 33, 897-920. http://dx.doi.org/10.1016/j.respol.2004.01.015

Geels, F. W., (2010b). A mulitlevel perspective on system innovation. In: Olsthoorn, X., Wieczorek, A. (Eds.), Understanding Industrial Transformation. View from Different Disciplines. Springer, Dordrecht.

Geels, F. W., (2012). A socio-technical analysis of low-carbon transitions: introducing the multi-level perspective into transport studies. Journal of Transport Geography, 24, 471-482. http://dx.doi.org/10.1016/j.jtrangeo.2012.01.021

Genus, A., Coles, A.-M., (2008). Rethinking the multi-level perspective of technological transitions. Research Policy, 37, 1436-1445. http://dx.doi.org/10.1016/j.respol.2008.05.006

Grin, J., Rotmans, J., Schot, J., Geels, F. W., \& Loorbach, D. (2010). Transitions to Sustainable Development. New Directions in the Study of Long Term Transformative Change. Routhledge, New York.

Hegger, L.T., van Vliet, J. (2007). Niche management and its contribution to regime change: the case of innovation in sanitation. Technology analysis \& strategic management.- Abingdon, Oxfordshire, 19(6), 729-746

Hekkert, M. P., Suurs, R. A. A., Negro, S. O., Kuhlman, S., Smits, R. E. H. M. (2007). Functions of innovation systems: a new approach for analysing technological change. Technological Forecasting \& Social Change 74, 413-432. http://dx.doi.org/10.1016/j.techfore.2006.03.002

Hodson, M., \& Marvin, S. (2010). Can cities shape socio-technical transitions and how would we know if they were? Research Policy, 39(4), 477-485. http://dx.doi.org/10.1016/j.respol.2010.01.020

Hoogma, R., Kemp, R., Schot, J., \& Truffer, B. (2002). Experimenting for Sustainable Transport. The Approach of Strategic Niche Management. Spon Press, London.

Hughes, T. P. (1983). Networks of Power: Electrification in Western Society 1880- 1930. John Hopkins University Press, Baltimore.

Jacobsson, S., \& Bergek, A. (2010). Innovation system analyses and sustainability transitions: contributions and suggestions for research. Environmental Innovation and Societal Transition 1(1), 41-57. http://dx.doi.org/10.1016/j.eist.2011.04.006

Kemp, R., \& Loorbach, D. (2003). Governance for Sustainability Through Transition 
Management. Paper for EAEPE 2003 Conference, Maastricht.

Kemp, R., van Lente, H. (2011). The dual challenge of sustainability transitions. Environmental Innovation and Societal Transition, 1(1), 121-124. http://dx.doi.org/10.1016/j.eist.2011.04.001

Kern, F. (2012). Using the multi-level perspective on socio-technical transitions to assess innovation policy. Technological Forecasting and Social Change, 79(2), 298-310. http://dx.doi.org/10.1016/j.techfore.2011.07.004

Kern, F., \& Smith, A. (2008). Restructuring energy systems for sustainability? Energy transition policy in the Netherlands. Energy Policy, 36(11), 4093-4103. http://dx.doi.org/10.1016/j.enpol.2008.06.018

Krakow. Elzen, B., Geels, F. W., Leeuwis, C., \& Van Mierlo, B., (2011). Normative contestation in transitions 'in the making': animal welfare concerns and system innovation in pig husbandry (1970-2008). Research Policy 40(2), 263-275. http://dx.doi.org/10.1016/j.respol.2010.09.018

Lachman, D. A. (2011). Leapfrog to the future: Energy scenarios and strategies for Suriname to 2050. Energy Policy, 39(9), 5035-5044. http://dx.doi.org/10.1016/j.enpol.2011.06.010

Lachman, D. A. (2013a). WANTED: energy system transition research in developing countries. In: Ramazzotti, A., Gravina, W. (Eds.), Developing Countries: Political, Economic and Social Issues. Nova Main Publishers, New York.

Lachman, D. A. (2013b). A survey and review of approaches to study transitions. Energy Policy 58 (2013) $269-276$

Loorbach, D. (2010). Transition management for sustainable development: a prescriptive complexity-based framework. Governance: An International Journal of Policy, Administration, and Institutions, 23(1), 161-183. http://dx.doi.org/10.1111/j.1468-0491.2009.01471.x

Loorbach, D., \& Rotmans, J. (2006). Managing transitions for sustainable development In: Olshoorn, X., Wieczorek, A.J. (Eds.), Understanding Industrial Transformation. Views from different disciplines. Springer, Dordrecht. http://dx.doi.org/10.1007/1-4020-4418-6_10

Loorbach, D., \& Rotmans, J. (2010). Transition Management and Strategic Niche Management. Dutch Research Institute For Transitions, Rotterdam.

Loorbach, D., van den Brugge, R., \& Taanman, M. (2008). Governance in the energy transition: practice of transition management in the Netherlands. International Journal Environmental Technology and Management, 9(2/3), 294-315. http://dx.doi.org/10.1504/IJETM.2008.019039

Lopolito, A., Morone, P., \& Sisto, R. (2011). Innovation niches and socio-technical transition: A case study of bio-refinery production, Futures, 43(1), 24-38. http://dx.doi.org/10.1016/j.futures.2010.03.002

Markard, J., Raven, R., \& Truffer, B. (2012). Sustainability transitions: an emerging field of research and its prospects. Research Policy, 41(6), 955-967, 
http://dx.doi.org/10.1016/j.respol.2012.02.013

Marody, M. (1996). Transition as a topic for sociological analysis. In: Sztompka, R. (Ed.), Building Open Societies and Perspectives of Sociology in East-Central Europe. ISA, Krakow.

Meadowcroft, J. (2009). What about the politics? Sustainable development, transition management, and long term energy transitions. Policy Sciences, 42, 323-340. http://dx.doi.org/10.1007/s11077-009-9097-z

Meadowcroft, J. (2011). Engaging with the politics of sustainability transitions. Environmental Innovation and Societal Transitions, 1, 70-75. http://dx.doi.org/10.1016/j.eist.2011.02.003

Musiolik, J., \& Markard, J. (2011). Creating and shaping innovation systems: formal networks in the innovation system for stationary fuel cells in Germany. Energy Policy, 39, 1909-1922. http://dx.doi.org/10.1016/j.enpol.2010.12.052

Nakamura, H., Kajikawa, Y., \& Suzuki, S. (2012w). Multi-level perspectives with technology readiness measure for aviation innovation. Sustainability Science, 8(1), 87-101. http://dx.doi.org/10.1007/s11625-012-0187-z

Nelson R., \& Winter, S. (1982). An Evolutionary Theory of Economic Change. Cambridge, Massachusetts: The Belknap Press of Harvard University Press.

OECD. (2011). Towards Green Growth - A Summary for Policy Makers. Organization for Economic Cooperation and Development, Paris.

Olsthoorn, X., Wieczorek, A. J. (Eds.) (2006). Understanding Industrial Transformation: Views from Different Disciplines. Springer. http://dx.doi.org/10.1007/1-4020-4418-6

Raven, R. (2006). Niche accumulation and hybridisation strategies in transition processes towards a sustainable energy system: an assessment of differences and pitfalls. Energy Policy, 35, 2390-2400. http://dx.doi.org/10.1016/j.enpol.2006.09.003

Raven, R. P. J. M., \& Geels, F. W. (2010). Socio-cognitive evolution in niche development: comparative analysis of biogas development in Denmark and the Netherlands (1973-2004). Technovation, 30, 87-99. http://dx.doi.org/10.1016/j.technovation.2009.08.006

Raven, R. P. J. M., \& Verbong, G. P. J. (2009). Boundary crossing innovations: case studies from the energy domain. Technology \& Society, 31, 85-93. http://dx.doi.org/10.1016/j.techsoc.2008.10.006

Raven, R., \& Verbong, G. (2007). Multi-regime interactions in the Dutch energy sector: the case of combined heat and power technologies in the Netherlands 1970-2000. Technology $\begin{array}{lllll}\text { Analysis } \quad \text { \& } \quad \text { Strategic } & \text { Management, } & \text { 19(4), }\end{array}$ http://dx.doi.org/10.1080/09537320701403441

Rehman, I. H., Kar, A., Raven, R., Singh, D., Tiwari, J., Jha, R., Sinha, P. K., \& Mirza, A., (2010). Rural energy transitions in developing countries: a case of the Uttam Urja initiative in India. Environmental Science \& Policy, 13(4), 303-311. http://dx.doi.org/10.1016/j.envsci.2010.03.012 


\section{Mll Macrothink}

Rip, A., \& Kemp, R., (1998). Technological change. In: Rayner, S., Malone, E.L. (Eds.), Human Choice and Climate Change, vol. 2. Battelle Press, Columbus, pp. 327-399.

Romijn, H., Raven, R., de Visser, I., (2010). Biomass energy experiments in rural India: insights from learning-based development approaches and lessons for Strategic Niche Management. Environmental Science \& Policy, 13(4), 326-338. http://dx.doi.org/10.1016/j.envsci.2010.03.006

Rotmans, J., Kemp, R., van Asselt, M., (2001). More evolution than revolution: transition management in public policy. Foresight, 3, 15-31. http://dx.doi.org/10.1108/14636680110803003

Schot, J., \& Geels, F. W., (2008). Strategic niche management and strategic innovation journeys: theory, findings, research agenda and policy. Technology Analysis \& Strategic Management, 20, 537-554. http://dx.doi.org/10.1080/09537320802292651

Shove, E., \& Walker, G. (2008). Transition management and the politics of shape shifting. Environment and Planning A, 40(4), 1012-1014. http://dx.doi.org/10.1068/a4004leb

Shove, E., \& Walker, G., (2007). CAUTION! Transitions ahead: politics, practice and sustainable transition management. Environment and Planning A, 39(4), 763-770. http://dx.doi.org/10.1068/a39310

Smith, A., \& Kern, F. (2009). The transitions storyline in Dutch environmental policy Environmental Politics, 18(1), 78-98.http://dx.doi.org/10.1080/09644010802624835

Smith, A., Voß, J., \& Grin, J., (2010). Innovation studies and sustainability transitions: the allure of the multi-level perspective and its challenges. Research Policy, 39(4), 435-448. http://dx.doi.org/10.1016/j.respol.2010.01.023

Sondeijker, S., Geurts, J., Rotmans, J., \& Tukker, A., (2006). Imagining sustainability: the added value of transition scenarios in transition management. Foresight 8, 15-30. http://dx.doi.org/10.1108/14636680610703063

STRN. (2010). A mission statement and research agenda for the Sustainability Transitions Research Network, www.transitionsnetwork.org, p. 27.

UNEP. (2011). Towards a Green Economy: Pathways to Sustainable Development and Poverty Eradication. United Nations Environment Programme, www.unep.org.

Van den Bergh, J. C. J. M., \& Oosterhuis, F. H. (2008). An evolutionary-economic analysis of energy transitions. In: van den Bergh, J.C.J.M., Bruinsma, F.R. (Eds.), Managing the Transition to Renewable Energy. Theory and Practice from Local, Regional and Macro Perspectives. Edward Elgar, Cheltenham.

Van den Bergh, J. C. J. M., Truffer, B., \& Kallis, G. (2011). Environmental innovation and societal transitions: introduction and overview. Environmental Innovation and Societal Transitions, 1(1), 1-23. http://dx.doi.org/10.1016/j.eist.2011.04.010

Van den Bosch S. J. M. (2010). Transition experiments. Exploring societal changes towards 


\section{Macrothink \\ Environmental Management and Sustainable Development \\ ISSN 2164-7682 \\ 2014, Vol. 3, No. 2}

sustainability. PhD thesis, Erasmus Universiteit, Rotterdam.

Verbong, G., Christiaans, W., Raven, R., \& Balkema, A. (2010). Strategic Niche Management in an unstable regime: biomass gasification in India. Environmental Science \& Policy, 13(4), 272-281. http://dx.doi.org/10.1016/j.envsci.2010.01.004

Verbong, G., Geels, F. W., \& Raven, R. (2008). Multi-niche analysis of dynamics and policies in Dutch renewable energy innovation journeys (1970-2006): hype cycles, closed networks and technology-focused learning. Technology Analysis \& Strategic Management, 20, 555-573. http://dx.doi.org/10.1080/09537320802292719

WCED (1987). Our Common Future. Final Report of World Commission on Environment and Development. WCED, New York.

Weber, M., \& Rohracher, H., (2012). Legitimizing research, technology and innovation policies for transformative change. Research Policy, 41, 1037-1047. http://dx.doi.org/10.1016/j.respol.2011.10.015

Wiek, A., Binder, C., \& Scholz, R. W. (2006). Functions of scenarios in transition processes. Futures, 38, 740-766. http://dx.doi.org/10.1016/j.futures.2005.12.003

Yuan, J., Xu, Y., \& Hu, Z., (2012). Delivering power system transition in China. Energy Policy 50, 751-772. http://dx.doi.org/10.1016/j.enpol.2012.08.024

\section{Copyright Disclaimer}

Copyright for this article is retained by the author(s), with first publication rights granted to the journal.

This is an open-access article distributed under the terms and conditions of the Creative Commons Attribution license (http://creativecommons.org/licenses/by/3.0/). 